\title{
The effect and the toxicity of Iranian oil dispersant (Pars 1) on rainbow trout
}

\author{
L. Bordbar ${ }^{1}$, S. Oryan ${ }^{1}$, M. Emtiyazjoo ${ }^{2} \&$ D. Farkhani $^{3}$ \\ ${ }^{I}$ Islamic Azad University of Science and Research Branch, Tehran, Iran \\ ${ }^{2}$ Islamic Azad University, Science and Marine Technology, North Branch, \\ Tehran, Iran \\ ${ }^{3}$ Research Institute of Petroleum Industry, Tehran, Iran
}

\begin{abstract}
Dispersants are oil spill response chemicals that are used to disperse floating oil in the water column. In this study the new oil dispersant Pars 1, which was produced by the Iranian Oil Company, was examined on 28-32 g rainbow trout. 96 hours acute toxicity of oil dispersant by itself and oil and dispersant combinations were tested in various concentrations. For each dose of experiment three treatments, one control and 30 fish were considered. The Lc50 by means of the Probit value and ANOVA test was determined. According to this method, the 96-hours Lc50 for Pars 1 and oil/dispersant are 47.7618 and $491.4277 \mathrm{mg} / \mathrm{lit}$. The effectiveness of Iranian oil dispersant (Pars 1) was compared with Gamlen OD4000 which is being used in south Iranian waters. By calculating the RET value and bioassay studies, the high effect and efficiency of Pars 1 has been proved.

Keywords: oil dispersant, oil toxicity, Oncorhynchus mykiss.
\end{abstract}

\section{Introduction}

Oil spill can have a serious economic impact on coastal activities and on those who exploit the resources of the sea. Simply, the effects of oil on marine life are caused by either the physiological nature of the oil or by its chemical components.

The most toxic component in oil tend to be those lost rapidly through evaporation when oil is spilt, because of this, lethal concentrations of toxic components lead to large scale mortalities of marine life (ITOPF [6]). 
Many studies have been made to determine the effects in the marine environment caused by oil pollution and cleaning operations. Straughan [11] declared that the greatly varying damage caused by oil pollution is due to a number of factors including type and quantity of oil, weather and wind, climate, methods used to combat the oil (Sweden et al [8]). Many investigations have been done in order to produce methods for counteracting the effects of oil spills (Lonning and Hagstrom [7]).

Dispersants are one options for reducing from oil spills (IPIECA [4]). They are a group of chemicals designed to be sprayed on to oil slicks to accelerate the process of natural dispersion. George [10] defined that massive death of all animals to limited effects indicated that cleaning operations are generally more destructive than the oil coverage (Sweden et al [8]).

Dispersants are complex mixtures, containing both hydrophobic and hydrophilic groups; therefore, they are typically sparingly soluble in both organic solvents and water [5].

The purposes of this study are:

1- To determine the 96-h acute toxicity of the new Iranian oil dispersant Pars 1.

2- To compare the effect and toxicity of oil dispersant Pars 1 with Gamlen OD4000 by itself and oil/dispersants combinations.

\section{Materials and methods}

Fish are more sensitive than some other marine animals such as bivalves, crustacean, etc. As a rule, species with a more active mode of life are also more susceptible than less mobile animals (Sweden et al [8]).

So rainbow trout with the average weight of 28-32 $\mathrm{g}$ were selected. The $96-\mathrm{h}$ acute toxicity of new Iranian oil dispersant Pars 1 and Gamlen OD4000 by itself and oil/dispersants combinations were tested. Export crude oil of Syri was used in this test.

The oil/dispersants combinations were 1:20 ratio. 18 aquariums with the volume of 138 lit were provided, 129.5 lit of each aquarium was considered as useful volume. All aquariums were cleaned carefully before and after each experiment.

All the experiments used the following concentrations: 10.5-21-42-84-168$336 \mathrm{mg} / \mathrm{lit}$ of dispersants and 168-336-672-1344 $\mathrm{mg} / \mathrm{lit}$ of oil/dispersants combinations.

The oil/dispersants combinations were 1:20 ratio, it means each concentration consisted of one part oil and 20 parts dispersants, for example 1:20 ratio of 168 $\mathrm{mg} /$ lit included $8 \mathrm{mg} / \mathrm{lit}$ dispersant plus $160 \mathrm{mg} / \mathrm{lit}$ oil per lit.

\subsection{Test organism}

Rainbow trouts were bought from a fish farm in Kelardash. They were then transported to an educational center in Karaj (5o kilometers west of Tehran). All fish were kept in concrete pond, free of oil related activities and industrials. 
All tests have been done under laboratory conditions; temperature was 13$15 \pm 1^{\circ} \mathrm{C}$ for dispersants and $20-21.5 \pm 1^{\circ} \mathrm{C}$ for oil/dispersants combinations dissolve oxygen was measured before and after each test (table 1 and 2). Aquarium water was aerated by two air compressors. Before introducing fish and because of their adaptation at least 24 hours before adding dispersants and oil/dispersants combinations to water, they were introduced to aquariums. The fish health was controlled before chemicals were used.

Table 1: Dissolved oxygen and temperature in both dispersants after 96-h experiment.

\begin{tabular}{|l|l|l|l|l|}
\hline \multirow{2}{*}{$\begin{array}{l}\text { Dispersants } \\
\text { concentrations } \\
(\mathrm{ppm})\end{array}$} & \multicolumn{2}{|l|}{ Pars 1 } & \multicolumn{2}{l|}{ Gamlen OD4000 } \\
\cline { 2 - 5 } & $\begin{array}{l}\text { Dissolved } \\
\text { oxygen } \\
(\mathrm{mg} / \mathrm{lit})\end{array}$ & $\begin{array}{l}\text { Temperature } \\
\left({ }^{\circ} \mathrm{C}\right)\end{array}$ & $\begin{array}{l}\text { Dissolved } \\
\text { oxygen } \\
(\mathrm{mg} / \mathrm{lit})\end{array}$ & $\begin{array}{l}\text { Temperature } \\
\left({ }^{\circ} \mathrm{C}\right)\end{array}$ \\
\hline 10.5 & 6 & 16 & 6 & 14 \\
\hline 21 & 6 & 16 & 6 & 14 \\
\hline 42 & 5 & 16 & 6 & 14 \\
\hline 84 & 5 & 16 & $5-6$ & 14 \\
\hline 168 & $5-4$ & 16 & 5 & 14 \\
\hline 336 & $5-4$ & 16 & 5 & 14 \\
\hline
\end{tabular}

Table 2: Dissolved oxygen and temperature in both oil/ dispersants combinations after 96-h experiment.

\begin{tabular}{|l|l|l|l|l|}
\hline \multirow{2}{*}{$\begin{array}{l}\text { Oil/dispersants } \\
\text { combinations } \\
(\mathrm{ppm})\end{array}$} & \multicolumn{2}{|l|}{ Oil+Pars 1 } & \multicolumn{2}{l|}{ Oil+Gamlen OD4000 } \\
\cline { 2 - 5 } & $\begin{array}{l}\text { Dissolved } \\
\text { oxygen } \\
(\mathrm{mg} / \mathrm{lit})\end{array}$ & $\begin{array}{l}\text { Temperature } \\
\left({ }^{\circ} \mathrm{C}\right)\end{array}$ & $\begin{array}{l}\text { Dissolved } \\
\text { oxygen } \\
(\mathrm{mg} / \mathrm{lit})\end{array}$ & $\begin{array}{l}\text { Temperature } \\
\left({ }^{\circ} \mathrm{C}\right)\end{array}$ \\
\hline 168 & 6 & 20.5 & 6 & 21.5 \\
\hline 336 & 6 & 20.5 & 5 & 21.5 \\
\hline 672 & 5 & 21.5 & 5 & 21.5 \\
\hline 1344 & 5 & 21.5 & 5 & 21.5 \\
\hline
\end{tabular}

Each bioassay consisted of 6 exposure concentrations and one control, with 3 replicates per concentration and 10 fish were used for each replicate.

Short term acute procedures were used throughout this investigation and rainbow trout were exposed 96 hours to both dispersants and oil/dispersants combinations.

\subsection{Test procedure}

Fish behavior and mortality were recorded daily over the 96-h period and dead fish were removed. During the experiment water was not changed and fish were 
not fed. Water temperature with the standard laboratory thermometer and dissolved oxygen were monitored before and after the test.

In order to calculate the volume of each dispersant, their density were measured in petroleum laboratory. (Table 3)

To prevent the fish from jumping out of the aquariums, all of the aquariums were covered by cloth net.

Table 3: Density of oil dispersants.

\begin{tabular}{|l|l|}
\hline Oil dispersant & Density $\mathrm{g} / \mathrm{cm}^{3}$ \\
\hline Pars 1 & 0.95 \\
Gamlen OD 4000 & 0.9098 \\
\hline
\end{tabular}

\subsection{Statistical analysis}

96-h acute lc50 of different experiments were estimated by Probit value [9] and the mortality was also analyzed by one-way ANOVA. 95\% confidence was obtained for each test. In addition to compare both of dispersants with each other, RET (Relative Effective Toxicity) value was calculated. Estimating RET needs to obtain DOR90 (Dispersants to Oil Ratio) and the dispersants Lc50 (Anderson et al. [2]).

\section{Results}

\subsection{Dispersants}

The water temperature during 96-h bioassays was stable and varied just over $\pm 1^{\circ} \mathrm{C}$ within each experiment. Dissolved oxygen was completely same in all tests, but after 96-h dissolved oxygen decreased in higher concentrations. Despite the higher concentrations such as 168 and 336 ppm make a thick layer of foam, which covered all water surface and reduced after 24 hours, within this time the water color in higher concentrations has been completely changed and became turbid. The water turbidity was very high as if the fish were absolutely invisible.

During the first 24 hours, all fish in 3 replicates of 168 and 336 ppm of both dispersants died.

Fish mortality was recorded daily (figure 1 and 2). The most mortality happened during the first 24 hours in both dispersants in all various concentrations.

These data were used to determine Lc50 for each of the experiments. The Lc50 values in both dispersants ranged from $42 \mathrm{mg} / \mathrm{lit}$ to $84 \mathrm{mg} / \mathrm{lit}$. Lc50 determined by the method exists in standard methods for examination of water and waste water book. Probit values were used to transform the mortality curve to linear patterns (figure 3 and 4).

The Lc50 estimate for 96-h acute toxicity of Gamlen OD 4000 was 55.26 $\mathrm{mg} / \mathrm{lit}$ and that for was Pars $147.76 \mathrm{mg} / \mathrm{lit}$. 


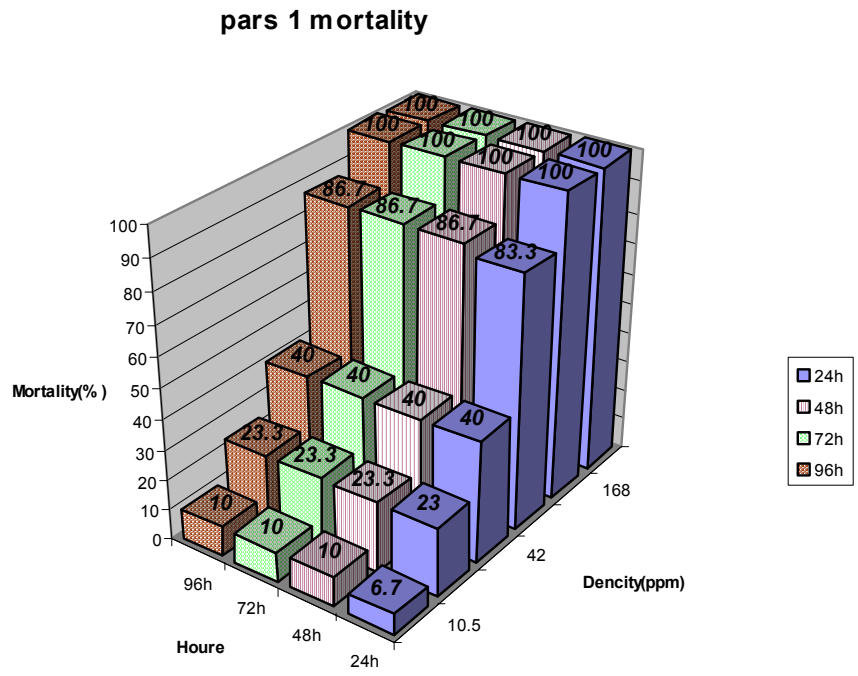

Figure 1: Histogram of Pars 1 mortality within 96-h.

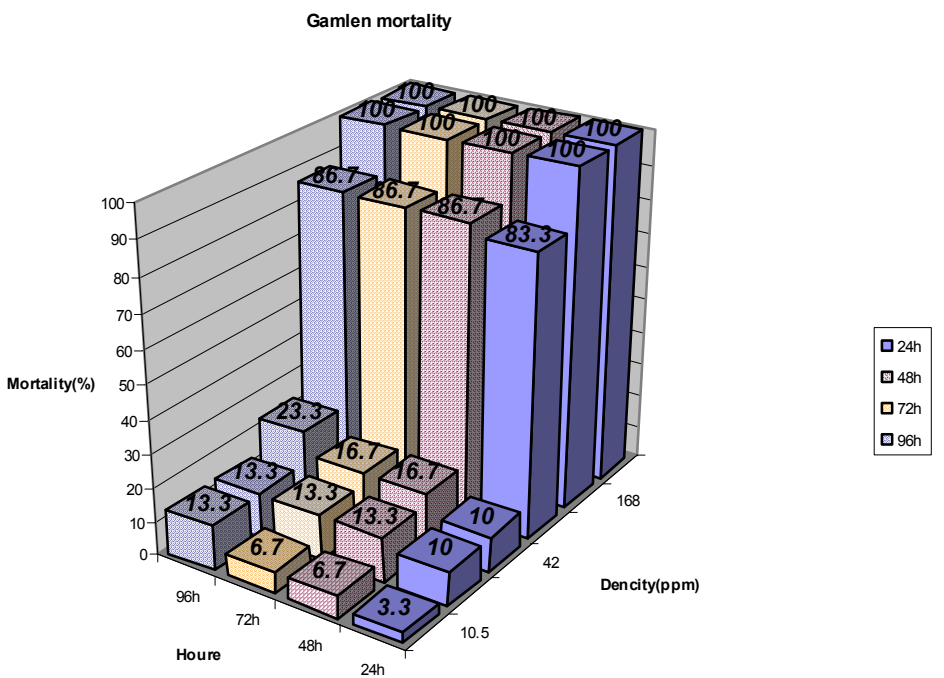

Figure 2: Histogram of Gamlen OD4000 mortality within 96-h. 


\subsection{Oil and dispersants combinations}

The same conditions as dispersants were done taken in these experiments. Water temperature and dissolved oxygen were recorded in table 2. Water temperatures were stable, dissolved oxygen varied in different concentrations, but it didn't show significant differences like what we have in dispersants alone.

The oil/dispersants combinations were in the ratio 1:20. Gamlen OD 4000 is being used in Iran's water by this ratio.

After the first 24 hours, the color of water in Syri crude oil and Gamlen OD 4000 combinations experiments turned to yellow and light brown. In the same concentrations the color of water in Syri crude oil and Pars 1 combination were darker than in the Syri oil and Gamlen OD 4000 combination.

Within the first 24 hours, all fish in 3 replicates of 1344 ppm of both oil and dispersants combinations died. Fish mortality was recorded daily (figures 5 and 6).

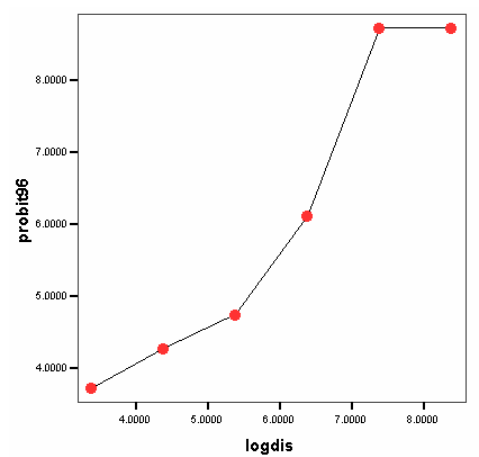

Figure 3: The determination of the Lc50 of Pars 1.

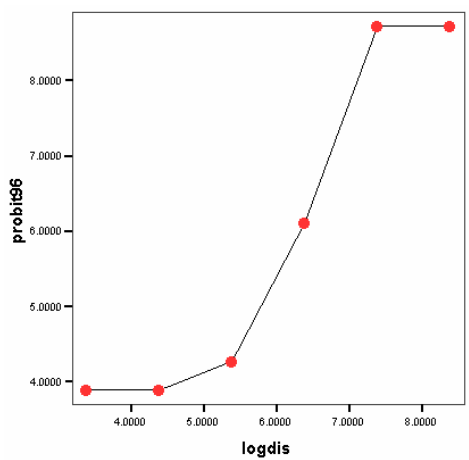

Figure 4: The determination of the Lc50 of Gamlen OD4000.

Lc50 determined by the mortality data and estimates for the 96-h acute toxicity of Syri crude oil and Gamlen OD 4000 combination ranged from 672 $\mathrm{mg} / \mathrm{lit}$ to $1344 \mathrm{mg} / \mathrm{lit}$ and for Syri crude oil and Pars 1 combination ranged from $336 \mathrm{mg} /$ lit to $672 \mathrm{mg} / \mathrm{lit}$.

Standard methods for examining water and waste water and Probit value were used to determine the Lc50 value (table 7 and 8 ).

The Lc50 estimates 96-h toxicity of Syri crud oil and Gamlen OD 4000 combination $722.21 \mathrm{mg} / \mathrm{lit}$ and for Syri crud oil and Pars 1 combination 491.42 $\mathrm{mg} / \mathrm{lit}$. 


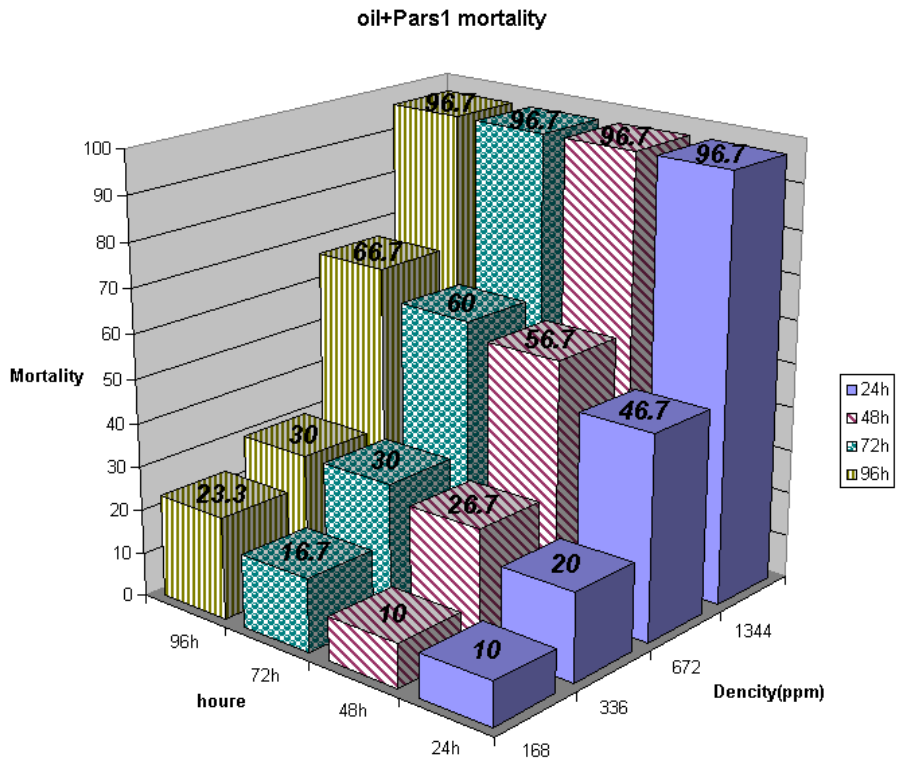

Figure 5: Bar chart of oil/Pars 1 combination mortality within 96-h.

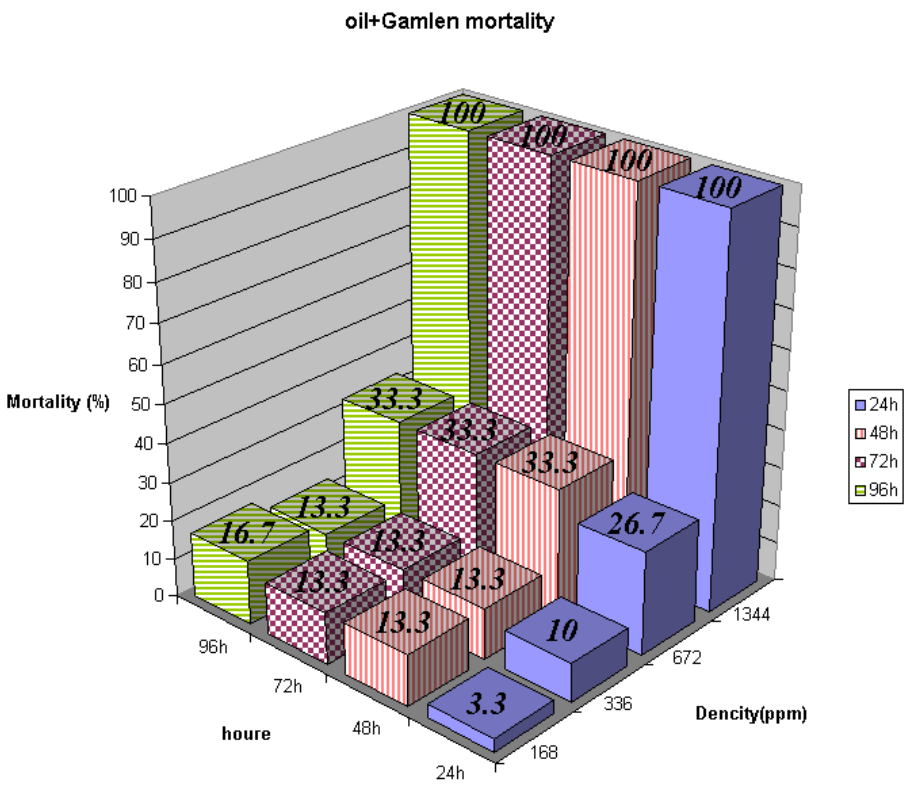

Figure 6: Bar chart of oil/Gamlen OD4000 combination mortality within 96-h. 


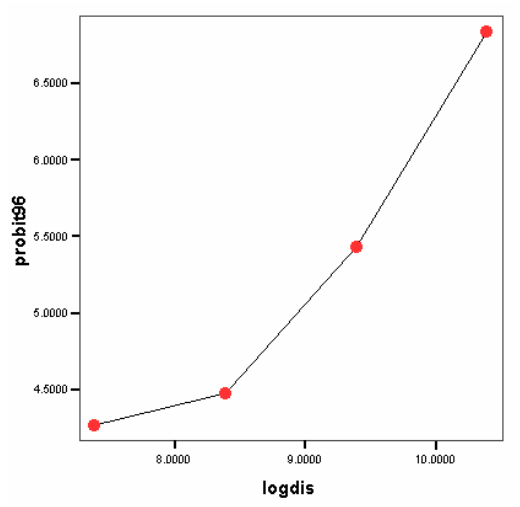

Figure 7: The determination of the Lc50 of oil/Pars 1 combinations.

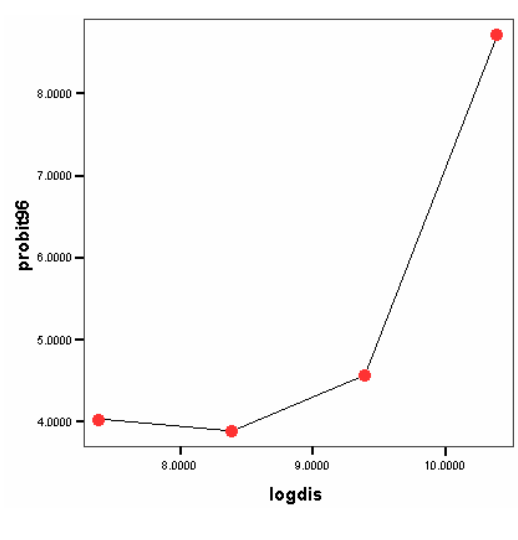

Figure 8: The determination of the Lc50 of oil/Gamlen OD4000 combinations.

\section{Discussion}

Acute aquatic toxicity is typically expressed by Lc50. The Lc50 is a concentration causing mortality in $50 \%$ of test organisms in a specific time period (typically 48 or $96 \mathrm{~h}$ ) (Ares and Clark [1]).

This study has examined the effect and toxicity of two different dispersants (Pars 1 and Gamlen OD 4000) and Syri crud oil and both dispersants combinations in 1:20 ratio during 96-h acute bioassays. There are few measured field data for dispersants. A maximum dispersants concentration of $13 \mathrm{ppm}$ has been measured at sea ( $0.6 \mathrm{~m}$ depth) (Ares and Clark [1]).

Therefore, the method has been developed for determining concentrations (10.5-336 ppm) of both dispersants and (336-1344 ppm) of Syri crud oil and dispersants combinations.

28-32 g of rainbow trout (oncorhynchus mykiss) were used in this research and as the observation of other researchers species with a more active mode of life are more susceptible than less mobile animals (Sweden et al [8]).

It seems that both dispersants have similar effects on rainbow trout behaviors and their biological functions, which is important for their survival.

Some great variations of LC50 value were found by different authors for defining the toxicity of materials. Differences in bioassay technique and condition of test animals and their life-stage may contribute to the results and it is probably for those reasons that the Lc50 value is various in different papers.

Due to the great variations, the toxic materials are preferably ranked in groups with respect to their 96-h Lc50 as proposed by Sprague and Carson [12].

$\begin{array}{ll}1-100 \mathrm{ppm} & \text { toxic } \\ 100-1000 \mathrm{ppm} & \text { moderately toxic } \\ 1000-10000 \mathrm{ppm} & \text { slightly toxic (Sweden } \text { et al [8]). }\end{array}$


According to this classification, both oil and dispersants combinations are moderately toxic.

The Lc50 value of Gamlen OD 4000 and Pars 1 was estimated $55.26 \mathrm{mg} / \mathrm{lit}$ and $47.76 \mathrm{mg} / \mathrm{lit}$. It is obvious that decreasing Lc50 value includes increasing toxicity, but the possibility exists that the conditions and locations of the spill will not require careful assessment to select a dispersant. Laboratory evaluation of chemical dispersants for use on oil spill at sea by J. W. Anderson and corporations shows a value for relative effectiveness and toxicity of dispersants to provide potential users a mean of selection.

The toxicity and effective results are shown in table 4. The DOR90 is the ratio of dispersants to oil required to disperse $90 \%$ of oil. When DOR90 values are combined with the 96-h Lc50 values, we can provide an estimate of the interaction between two selection criteria.

Table 4: Relative effectiveness and toxicity of oil dispersants.

\begin{tabular}{|l|l|l|l|}
\hline Oil dispersant & $\begin{array}{l}\text { Dispersants to oil } \\
\text { ratio } \\
\text { (DOR90) }\end{array}$ & 69-h Lc50 PPM & RET \\
\hline Pars 1 & 0.06 & 47.76 & 12.56 \\
Gamlen OD4000 & 0.14 & 55.26 & 26.34 \\
\hline
\end{tabular}

RET: relative effectiveness toxicity $=\left(\mathrm{DOR} 90^{*} 10^{4} / \mathrm{Lc} 50\right)$

The first column in Table 4 shows the RET which is relative effective toxicity. When DOR90 increases in the number or the Lc50 decrease, the RET becomes larger, which indicates a less acceptable product. Thus the chemicals with the lowest RET values (best products) are those that require less dispersant volume to disperse a spill or are less toxic (higher Lc50 value) or when two factors are combined to produce the lowest ratio.

J. W. Anderson and corporations showed the RET value of Corexit 9527 is lower than Corexit 7664, although Corexit 7664 has a higher 96-h Lc50 than Corexit 9527 and their Lc50 values differences are so distinguished.

It should be noted that this system gives equal weight to the toxicity and effectiveness of dispersants (Anderson et al [2]).

According to the RET value, Pars 1 is better than Gamlen OD 4000 and both Syri crud oil and dispersants combinations are ranked in moderately toxic materials.

\section{Conclusion}

Dispersants are oil spill chemicals that are used to disperse floating oil in to water column.

There are several important factors in making decisions whether to use an oil spill chemical or not. Although the toxicity of an oil dispersants is one of the important factors, the relative effectiveness toxicity is the last determining value to select oil dispersant. 
However, laboratory test methods are not completely matched to the wild life. It is recommended that oil dispersant toxicity and the relative effectiveness toxicity be tested under laboratory conditions.

\section{Acknowledgments}

This work was supported by Iran's Continental Oil Company and I wish to thank the director of this company and all the staffs for supplying oil and dispersants and also thank to Islamic Azad University Science and Research Branch for financial supporting of this article to be presented in conference. My especial thank to Dr.Shirban for editing the article and Miss Soltani for her statistical assistance.

\section{References}

[1] Ares, A. g, Clark, J. R, Aquatic toxicity of two corexit dispersants, Chemosphere 40(2000), 897-906,1999.

[2] Anderson, J. W, McQuerry, D.L, Kiessar, S. L, Laboratory evaluation of chemical dispersants for use on oil spills at sea, Environ. Sci. Techno, 19, 454-457, 1985.

[3] Adams, G. C, Klerks, P.L, Belonger, S.E, Dantin, D, The effect of the oil dispersants Omni-clean on the toxicity of fuel oil NO.2 in the two bioassays with the sheephead minow Cyprinodon variegatus, Chemospher, Vol.39, No12, 2141-2157, 1999.

[4] Dispersants and their role in oil spill response, A summary of IPICECA report, Vol 5, Second edition, 2001.

[5] http://en, wikipedia.org/wiki/surfactant

[6] www.ITOPF,com/dispersa.html

[7] Lonning, S, Hagstrom, B.E, Deleterious effect of Corexit 9527on fertilization and development, Marine pollution bulletin, 1979.

[8] Sweden, M, Granmo, A, Kollberg, S, effects of oil dispersants and oil emulsions on marine animals, Water research pergamon press, Vol 7,1649-1672, 1973.

[9] Standard Methods for Examination of Water and Wastewater, American Public Health Assoc., American Water Pollution Control Federation American Water Work Assoc $19^{\text {th }}$ Ed. 1995.

[10] George, J.D. The effect of pollution by oil and oil-dispersants on the Common inertial polychaetes, J. appl. Ecol. 8,411-420, 1971.

[11] Sraughan, D. Factors causing environmental changes after oil spill. Journal of petroleum technology. March 1972.

[12] Sprauge, J.B, Carson, W. G, Toxicity tests with oil dispersants in connection with oil spill at the Chedobucto bay, Nova Scotia, Ottawa, Fisheries research board of Canada. 1970. 